\title{
EMPRENDEDOR Y EMPRESARIO: UNA CONSTRUCCIÓN DESDE LA DINÁMICA DEL PENSAMIENTO ECONÓMICO ${ }^{1}$
}

\author{
Wilfrido de Jesús Primo Tapia ${ }^{2}$ \\ Héctor Felipe Turizo Tapia ${ }^{3}$
}

Para citar este artículo: Primo, W., y Turizo, H. (2016). Emprendedor y empresario: una construcción desde la dinámica del pensamiento económico. Inquietud Empresarial. Vol. XVI (1), 13-52

Fecha de recepción: 13 de septiembre de 2015

Fecha de aceptación: 19 de abril de 2016

\footnotetext{
1 Artículo de revisión del Grupo de Investigación "Comercio y Comportamiento del Consumidor" de la Universidad de Cartagena.

${ }^{2}$ Economista (Universidad de Cartagena, Colombia). Magíster en Desarrollo Empresarial (Universidad del Magdalena, Colombia). Doctorando en Ciencias Económicas (Universidad del Zulia, Venezuela). Docente de la Universidad de Cartagena en el área de economía para el Programa Administración de Empresas. Grupo de Investigación “Comercio y Comportamiento del Consumidor” E - mail: wprimot@unicartagena.edu.co

${ }^{3}$ Economista (universidad del Atlántico-Colombia). Magíster en Desarrollo Empresarial. (Universidad del Magdalena-Colombia). Funcionario de la escuela superior de Administración Pública - ESAP. E - mail: hectturi@esap.edu.co
} 


\title{
Resumen
}

El nacimiento de empresas y la supervivencia de otras en un mercado competitivo está sujeta al papel que desempeñan emprendedores y empresarios. En la historia del pensamiento económico se pueden encontrar contribuciones a la formación de empresario y emprendedor. Este trabajo, expone los principales enfoques del pensamiento económico que han contribuido con el desarrollo del concepto de empresario y emprendedor. Al respecto, se abordan las concepciones de las escuelas económicas, desde la óptica de los representantes más relevantes, para comprender al empresario como agente que produce beneficios mediante la gestión de recursos; adicionalmente, se muestra cómo se concibe al emprendedor, en el rol de innovador, de agente de cambio, y oportunista para crear nuevas empresas o aprovechar oportunidades de negocios. Finalmente, se presenta una reflexión sobre los esfuerzos de los estados latinoamericanos para desarrollar la mentalidad emprendedora y la creación de empresas, con el objeto impulsar el crecimiento económico de los países y la región en general.

Palabras claves: Desarrollo empresarial, empresario, emprendedor, innovación y desarrollo económico.

\section{Entrepreneur and entrepreneur: a construction from the dynamics of economic thinking}

\begin{abstract}
The birth of companies and the survival of others in a competitive market is subjected to the role of entrepreneurs and businessmen. Alongside of the history of economic thought it can be found contributions to the formation of a businessman and entrepreneur. This research presents the main approaches of economic thought that have contributed to the development of the concept of businessman and entrepreneur. In this regard, the concepts of economic schools are addressed from the perspective of the most important representatives, in order to understand the entrepreneur as agent producing benefits through resource management. Additionally, it shows how the entrepreneur is conceived in the role of innovator, agent of change, and opportunist to create new businesses or take advantage of business opportunities. Finally, it is presented a reflection on the efforts of Latin American states to develop the entrepreneurial mindset and business creation, in order to boost economic growth of the countries and the region in general.
\end{abstract}

Key words: business development, entrepreneur, entrepreneur, innovation and economic development. 


\section{Empresário e empreendedor: um edifício da di-namic do pensamento econômico}

\section{Resumo}

O nascimento de empresas e outras sobrevivência em um mercado competitivo é Suje-ta ao papel dos empresários e homens de negócios. Na história do pensamento econômico pode ser encontrado contribuições para a formação do empregador e compromete-dor. Este trabalho apresenta as principais abordagens do pensamento econômico que con-contribuiu para o desenvolvimento do conceito de empresário e empreendedor. Neste sentido, as concepções abor-dan de escolas econômicas, a partir da perspectiva dos representantes mais importantes, para entender o empreendedor como benefícios agente de produção através de uma gestão de recursos; Além disso, ele mostra como o empresário é concebido no papel de inovador, agente de mudança, e oportunista para criar novos negócios ou tirar proveito de oportunidades de negócios. Finalmente, uma reflexão sobre os esforços dos Estados latino-americanos tem de desenvolver o espírito empresarial e criar em-barragens, com a impulsionar o crescimento económico dos países e da região como um objeto inteiro.

Palavras chave: Desenvolvimento de negócios, empreendedor, empreendedor, inovação e económica desenvolver - llo.

\section{Introducción}

Generalmente, la economía se ha centrado en el análisis relacionado con la oferta, la demanda, los mercados, los precios, el desempleo, la inflación (Terapuez y Botero, 2007) y el comportamiento del sistema económico, dejando de lado el concepto de empresario y emprendedor, aunque lo define como un importante factor de producción - habilidad empresarial - siempre ha mostrado mayor interés por la tierra, el trabajo y el capital; recientemente por la tecnología y el conocimiento.

Para muchos economistas, en la teoría económica, el empresario y emprendedor han sido asociados al factor trabajo, haciéndolo ver como un trabajo común y corriente. Aun así, el papel de emprendedor, es un talento especial que no es tan común como el de un trabajador ordinario.

En este orden de ideas, la capacidad emprendedora de cada individuo ha sido asociada al rol del empresario que asume riesgos, hace innovaciones y gestiona procesos de cambio en su organización y en el contexto. Durante el desarrollo y construcción del pensamiento económico cada una de las escuelas y economistas han dado una interpretación del papel que ha cumplido el empresario como agente dinamizador de la actividad económica y gestor del crecimiento y desarrollo 
económico. Aunque a lo largo de la historia lo que más ha llamado el interés de los economistas es responder porqué unos países son más ricos que otros. Esta preocupación siempre ha sido resuelta desde el punto de vista cuantitativo, es decir, que las variables que influyen en el desarrollo económico tienen un carácter exógeno. Desde esta perspectiva se dejan de lado otras variables como el emprendimiento y el empresario que, entre otras, podrían tener mayor peso a la hora de dar respuesta sobre la riqueza o no de algunas naciones.

Tradicionalmente, las figuras de empresario y emprendedor, se han identificado, en la mayoría de los casos, en una misma persona. Por lo anterior, es necesario aclarar que empresario es quién dirige, es decir, el responsable del buen funcionamiento de la empresa; el emprendedor puede tomar iniciativas, asumir riesgos y aprovechar oportunidades para sacar beneficios en la creación de nuevas empresas, por ello es un innovador, que, aunque no aporte capital como lo hace el empresario, sus habilidades lo hacen muy diferente. (Véase Ilustración 1)

Este trabajo constituye una recensión de la construcción del concepto de empresario y emprendedor a través de la evolución del pensamiento económico y desde los diferentes aportes y puntos de vista de escuelas de pensamiento y economistas representativos. Así pues, también pretende mostrar cómo se ha interpretado el rol, que tanto, empresario como emprendedor han desempeñado durante la historia de las ideas económicas, y lo más importante, la función que cumple como generador de riqueza.

\section{Objetivo}

El objetivo de este estudio es analizar, desde la dinámica de las escuelas de pensamiento económico, los aportes que han contribuido con la construcción del concepto de emprendedor y empresario, con la finalidad hacer una caracterización desde los roles y funciones que desempeñan en el mundo empresarial o de negocios. Por lo anterior, el estudio, desde el punto de visto conceptual, trata de responder las preguntas: ¿Cuáles son los aportes que desde las escuelas de pensamiento económico han contribuido en la formación del concepto de emprendedor y empresario? ¿Cuáles son las características, desde las teorías económicas, que diferencian a un empresario de un emprendedor? 
Tabla 1. El empresario y el emprendedor como agente dinámico en la actividad económica.

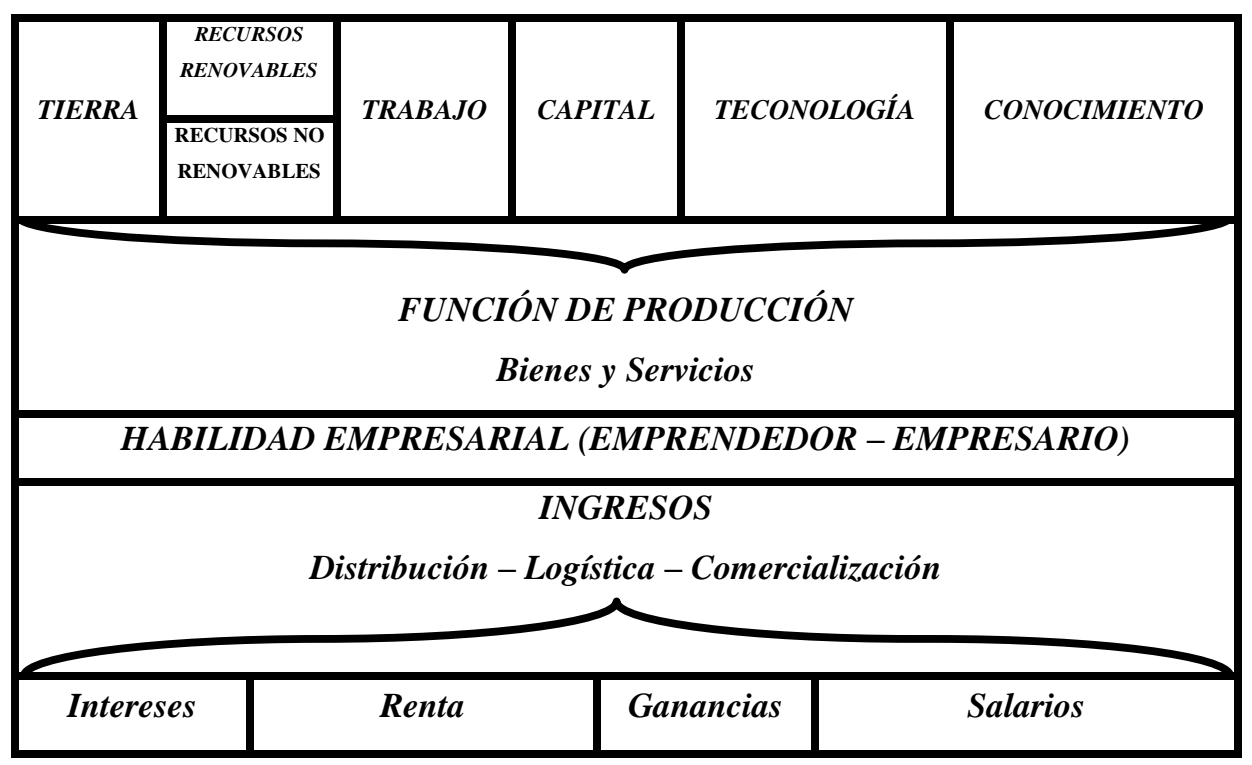

Fuente: Grebel (2007, p. 148). Adaptado por los autores.

\section{Marco Teórico}

El marco referencial de este trabajo está dado por las teorías que estructuraron el cuerpo doctrinario de la economía, que, a través de estudios del desarrollo de las ideas económicas, se consolidó en escuelas de pensamiento. En consecuencia, se apoya en las teorías expuestas por cada uno de los más relevantes pensadores, cuyos aportes, ayuden a interpretar el papel del emprendedor y empresario. De esta manera, se inicia con los lineamientos mercantilistas, pasando por los aportes fisiócratas, luego por los clásicos y neoclásicos, sumando los de la escuela socialista y por último con los economistas y escuelas más recientes.

Por lo anterior, el tema se ubica en el estudio en las aportaciones que hicieron economistas y escuelas de pensamiento durante el desarrollo histórico económico de la humanidad y de cómo desde sus teorías definen o conceptúan el emprendedor y el empresario como actores y gestores de desarrollo económico. Siendo así, el paradigma sobre el cual se trabaja es el papel del empresario y del emprendedor interpretado desde la óptica de las escuelas de pensamiento económico. Especificando aún más, la particularidad estudiada se enmarca dentro de la función que cumplen ambos como agentes dinámicos y generadores de cambio y progreso. 


\section{Metodología}

Este estudio tiene un carácter histórico - documental, dado que pretende hacer un análisis de sobre las contribuciones que, desde las escuelas económicas, que permitan mostrar la construcción del concepto de emprendedor y empresario; comprende la función que cumplen en la empresa y la sociedad, y sus características más importantes. Por consiguiente, pretende mostrar la relación del empresario y el emprendedor, con el progreso de las naciones.

Para tal fin se recurre a instrumentos o documentos escritos sobre la historia del pensamiento económico, complementadas con documentos representativos y bibliografías sobre el tema de emprendimiento y empresario. Posteriormente, se toman los aportes más significativos para el estudio, haciendo un recorrido cronológico desde los Mercantilistas, hasta los institucionalistas, enfatizando en elementos que describen el rol emprendedor y el rol del empresario con el objeto de hacer una caracterización.

\section{Paralelo entre empresario y emprendedor}

En este orden de ideas, es preciso comparar y contrastar, las categorías empresario y emprendedor de tal manera que permita independientemente del rol que desempeñe cada uno, ubicar su origen para tomar los elementos históricos de referencia, con el propósito de entender la función que cumplen, desde los diferentes enfoques o escuelas de pensamiento. Por lo anterior, se inicia con la definición de emprendedor, posteriormente con empresario y por último se muestra en conjunto las relaciones entre ambos, sin dejar de lado la influencia que tiene como variables generadoras de crecimiento y desarrollo económico.

El proceso emprendedor Según Zimmerer y Scarboraugh (Zimmerer y Scarborough, N, 1996), está fundamentado en la teoría económica (Caldera, Rodríguez, y Moreno). En este sentido exponen que J.B. Say fue el primero en conceptualizar el término emprendedor, alrededor de 1800. Para Say, el emprendedor "cambia los recursos económicos de un área de muy baja productividad hacia otra área de la más alta productividad y rendimiento". Además, afirman que la función más importante del emprendedor, era hacer cosas diferentes, dicho de otro modo, el cambio; poniéndolo como en el centro tanto del proceso de producción como de la teoría de distribución, lo cual iría más tarde a influenciar en otros teóricos de la economía.

En este sentido, el emprendedor representa la figura estelar de la economía de mercado y se encarna en un agente con determinadas características para crear e innovar, también para adoptar las decisiones necesarias que le permitan acometer 
con éxito nuevos proyectos o negocios y saber asumir los riesgos que se encuentran en este desempeño particular.

Del mismo modo, la acción del emprendedor es siempre comenzar o acometer una obra, un empeño o un negocio, bien de nueva creación o que representa una innovación, más o menos radical, sobre lo ya existente, y que, en cualquier caso, encierra dificultades y riesgos singulares y complejos, a la vez, que entraña motivación, ante los diferentes desafíos y retos.

Por otro lado, el término "empresario" tiene muchas connotaciones y la literatura sobre el tema es diversa. Existe, por ejemplo, bibliografía sobre el empresario como factor de producción, coordinador y su relación con el equilibrio, manager y líder carismático, innovador, factor de crecimiento económico, y otros (Londoni, 2006) A pesar de esta relativa abundancia de significados, los libros de texto de economía tratan el tema de manera parcial o, simplemente, no lo mencionan de forma directa. (Calvin y Francis, 1999).

El término parece haber surgido en el siglo $\mathrm{XV}$, y se aplicaba a personas que corrían riesgos, especialmente durante las guerras. Ya para el siglo XVI, el término se refería a "un hombre de negocios a gran escala que acordó proveer, asumiendo la responsabilidad de combinar los factores de producción por su cuenta y riesgo". (Elkjaer, 1991) Probablemente el origen de la palabra entrepreneur, es celui qui entreprend, que implica una persona activa y con iniciativa. La palabra tiene su origen en el verbo entreprendre, que tiene un significado similar a "lograr que las cosas se hagan". Hasta el siglo XVI, entrepreneur significaba: (1) tomar, apoderarse de (saisir); (2) sorprender, descubrir (surprendre). ${ }^{4}$

Se entiende, entonces, que la persona empresaria (en el idioma inglés conocido como "entrepreneur") es aquel agente, con la energía, el dinamismo y la flexibilidad para resolver los problemas y además ambiciosa e inquiridora. Este tipo características y estrategias provienen del latín quaero que significa "buscar". La teoría moderna del empresario está principalmente interesada en estudiar la característica primaria del empresario: la búsqueda de, o descubrimiento de, nuevo conocimiento (Heredira, 2013).

Quizás, desde algunas escuelas de pensamiento, el papel del empresario, no lo definen con claridad, pero dejan entrever sus teóricos, que es un elemento importante, ya sea en el modo de producción capitalista o socialista. Con esta perspectiva, precisamente, no se puede pasar por alto fácilmente el papel y la

\footnotetext{
${ }^{4}$ Elkjaer (1991, 805), citando a Bloch y Wartburg (1950). Hoselitz (1962), ofrece un análisis aún más detallado de los orígenes lingüísticos del término entrepreneur y su uso antes de la aparición de Cantillon.
}

Volumen XVI (1) (Enero - Diciembre 2016). ISSN 0121 - 1048 
contribución del empresario, dado que en el mecanismo de precios el empresario es pasivo e invisible. Pero, cuando hay desequilibrio, incertidumbre, información imperfecta o racionalidad limitada, el papel del empresario es suplir al mecanismo de precios.

La figura del empresario es introducida en el análisis del proceso como el agente que descubre y explota oportunidades que habilitan el tránsito desde el desequilibrio hacia el equilibrio. Hayek indica que los empresarios son una clave de la coordinación:

No puede decir nada pero que, en determinadas condiciones, el conocimiento y las intenciones de los diferentes miembros de la sociedad se supone que vienen más y más en un acuerdo o, por decirlo de la misma cosa en menos general y menos precisa, pero más concreta, que las expectativas de la población y en particular de los empresarios se volverán más y más correcto (Hayek, 1937).

Siempre que los mercados sean abiertos y estén libres de interferencia externa por parte de las autoridades, los empresarios actuarán promoviendo ajustes equilibrantes. El proceso del mercado es, en este sentido, necesariamente competitivo y empresarial. (Von Mises y Kirzner, 1973) En términos de bienestar, sujetar el ingreso de los empresarios a un sector rentable tiene efectos inversos a los deseados: retrae la división del trabajo, el incremento de la productividad y la acumulación de capital. Una sociedad en la que existe competencia entre empresarios es capaz de coordinar, pero también de orientar fuerzas para liberar y economizar recursos, por un lado, y lograr el crecimiento económico, por otro (Kirzner, 1997).

\subsection{El espíritu empresarial mercantilista}

Los nuevos descubrimientos del siglo XV, marcaron la transición de Europa hacia otra época en que el mundo europeo se vio colmado de sorpresas. Nuevas tierras, nuevas confirmaciones de esa teoría con la redondez de la tierra, el descubrimiento de pueblos hasta ahora desconocidos y el encuentro de riquezas insospechadas, transformaron las costumbres medievales y originaron una nueva mentalidad (Ramírez, 2002). La apertura de minas de oro y plata del nuevo mundo y el acceso a nuevos recursos naturales estimularon el comercio y el desarrollo de economías basadas en dinero (Ramírez, 2002). Esto quiere decir que, el espíritu mercantilista, se traducía en el afán de obtener utilidades, buscando el lucro a través de empresas y negocios que permitieran la acumulación de metales preciosos y acrecentar la riqueza. Este cambio de mentalidad de la sociedad 
europea, surgida de las ideas emancipatorias de Lutero y Calvino, transformaron la conducta social del hombre y su destino después de la muerte. Fue así como el protestantismo y especialmente el calvinismo promovió el espíritu mercantilista de ahorro, la ambición económica y la adquisición de riquezas por medio de sagaces tratos y libertar en toda suerte de operaciones económicas (Ramírez, 2002).

De esta manera empezaron a funcionar las primeras empresas de negocios, tal cual, como las firmas comerciales funcionan hoy, surgieron por los descubrimientos, las conquistas y las colonizaciones, apoyadas en el nuevo espíritu protestante. Los mercaderes, que se lucraban de todo tipo de actividad, sirvieron de base para la consolidación de un fuerte Estado que favoreció la expansión del comercio y la protección, tanto de la competencia como de otros ataques. Desde ese momento aparecen, como entes, las primeras sociedades o firmas comerciales con personería jurídica, diferentes a las personas naturales, como la Compañía de las Indias Orientales, en Inglaterra. Es necesario resaltar que el nuevo elemento de la sociedad es el empresario, con afán permanente de obtener beneficios y acumular riqueza. Junto a esto surgen nuevas estrategias de gestión de gestión empresarial, como la publicidad, los precios escritos en las mercancías y el uso del papel moneda. También aparecen los primeros bancos y nuevos instrumentos para garantizar deudas y financiar negocios.

En este sentido, el perfil del empresario mercantil estaba fundamentado bajo el principio de lucro, pareciéndose al capitalista afanado por conseguir riquezas, exponiendo lo mínimo, dado el sentido proteccionista y conservador del empresario.

\section{2. ¿Emprendimiento, de los fisiócratas o de los mercantilistas?}

La fisiocracia que significa "norma o ley de la naturaleza", se desarrolla en Francia a mediados del Siglo XVII y parte del XVIII. Considerada, por muchos, como la primera escuela económica importante. El más destacado, en tomar como referencia el papel del empresario, fue Richard Cantillón (1680-1734), cuya obra de 1755, Essai sur la nature du commerce en general (Ensayo sobre la naturaleza del comercio en general, escrita entre 1730 y 1734). Precisamente fue, Cantillón, quien introdujo por primera vez el concepto de empresario, aduciendo que la economía funcionaba como un sistema de mercados organizados e interrelacionados, de tal manera, que alcanzaban un tipo de equilibrio, dada la relación entre individuos e instituciones. El sistema tiende a ajustarse por el libre juego de los empresarios egoístas que dirigen <<todo el trueque y la circulación del Estado > (Ekenlund, Robert, y Herbert, 2003). Los empresarios, como otros 
participantes, están interrelacionados recíprocamente, en tanto que son consumidores y clientes los unos respecto a los otros.

En consecuencia, el mercado es concebido como un espacio de competencia permanente, entendido, más bien, como un proceso de rivalidad entre los contendientes para ganar clientes. En esta competencia, el papel del empresario, es vital y omnipresente, puesto que reacciona ante los movimientos de precios en los mercados específicos. Es destacable también, la posición dada al empresario en el estrato económico-social, lo cual, lo llevó a plantar:

Cabe afirmar que, si se exceptúan el príncipe y los terratenientes, todos los habitantes de un Estado son dependientes; que pueden, éstos, dividirse en dos clases: empresarios y gente asalariada; que los empresarios viven, por decirlo así de ingresos inciertos, y todos los demás cuentan con ingresos ciertos durante el periodo que ellos gozan, aunque sus funciones y sus rangos sean muy desiguales. El papel que tiene una paga, el cortesano que cuenta y el criado que dispone de un salario, todos ellos quedan incluidos en este último grupo. Todos los demás son empresarios, y ya se establezcan con un capital para desenvolver su empresa, o bien sean empresarios de su propio trabajo, sin fondos de ninguna clase, pueden ser considerados como viviendo en un modo incierto, los mendigos mismos y los ladrones son empresarios de esta naturaleza. (Ensayo, p. 43)

Vale la pena señalar, que Cantillón distingue entre empresario capitalista y emprendedor, el primero tiene respaldo de su capital y es el propietario, fabricante o comerciante y el segundo es quien trabaja por sí sólo o dependiendo de su propio trabajo. No obstante, los empresarios enfrentan la incertidumbre del mercado y corren riesgo, pero, es aún más incierto, el juego del empresario que no cuenta con capital que el capitalista mismo; dado que las ventas y los precios de venta son inciertos y no fijos, su ganancia se convierte asimismo en un residuo incierto, al respecto Cantillón anota,

Estos empresarios no pueden saber jamás cual será el volumen del consumo en su ciudad, ni cuánto tiempo seguirán comprándoles sus clientes, ya que los competidores tratarán, por todos los medios, de arrebatarles la clientela: todo esto causa tanta incertidumbre entre los empresarios, que cada día alguno de ellos caen en bancarrota (Ensayo, p. 41)

Por ello, Cantillón, quiso establecer el principio, de que todo el trueque y circulación del Estado, se realizara por mediación de los empresarios, asignando a la actividad empresarial como esencia la competencia y viceversa. (Ekenlund, Robert, y Herbert, 2003).

En resumen, Richard Cantillón, con rigor y criterio, se dedicó a analizar los dos factores de la producción de riqueza nacional: tierra (lo natural) y trabajo 
(productivo) (lo humano). Es el primer economista en desarrollar esta idea. Al combinar ambos factores en el balance comercial nacional se debería procurar que los bienes importados tengan mayor proporción del factor natural - tierra, al mismo tiempo que los exportados posean mayor parte del valor factor - trabajo. Cuanto más producto natural tenga una economía nacional, tantas más personas podrá mantener, pues el hombre vive del consumo de la materia, no del valor creado en el trabajo.

Frente a la idea del bien común y de la necesidad de actitudes de cooperación, planteó el problema del riesgo y la incertidumbre, inherentes a la actividad empresarial, en un horizonte individualista, y clasista (por esta razón se le considera precursor del concepto de empresario como sujeto que asume riesgos). Para él sólo cuentan dos clases: la de los independientes, príncipes y grandes propietarios, o la de los dependientes que se dividen a su vez en empresarios y asalariados. Los empresarios reciben un salario inseguro (no conocen con seguridad los beneficios que puede aportarle su negocio), los otros, un salario seguro. Cantillón, es contrario, a la concepción colectiva del comportamiento cooperativo, que había propugnado antes el Mercantilismo.

Del mérito, esquivo para Cantillón, Adam Smith, que al criterio de muchos el "Padre de la Economía Política" y que como ningún otro fue citado por éste es su obra cumbre; lo es quizás porque su vida intelectual se desarrolla en un mercantilismo tardío, pocos años antes del florecimiento de la fisiocracia. Es por ello, muchos dicen, que su teoría muestra la apertura a las nuevas ideas del emprendedor y empresario, no es mercantil, pero que tiene la viveza del individualismo mercantil; también mucho de la fisiocracia, por el valor dado a la tierra en la producción y así del liberalismo económico, muy contrario, al pensamiento proteccionista mercantil.

\subsection{Los economistas clásicos y la empresarialidad}

Si se asocia el papel del empresario, no sólo al dueño de la empresa, o en términos más apropiados, dentro de la economía clásica, al capitalista. Éste se puede asociar más al empresario, con base en las necesidades del mercado y el afán de lucro, busca la maximización del beneficio aumentando la productividad del trabajo, a través de la especialización y el mejoramiento de las habilidades del trabajador. Por ello, se puede identificar con un aventajado empresario, aunque su papel no sea explícito en la definición de empresario o emprendedor, se muestra como el dueño del negocio. De esta manera, los economistas clásicos, representados por Adam Smith, David Ricardo y J.S. Mill, incluido Carlos Marx, concebían al empresario como el propietario del negocio, es decir, todo aquel que era propietario del capital. Durante este periodo del capitalismo, que aún se encontraba en proceso de gestación, no existía diferencia entre el empresario y el 
capitalista, las individualidades empresariales primaban y ocupaban una posición relevante en la sociedad.

Es necesario resaltar que no hicieron esa gran diferenciación, puesto que existían complejas dificultades de carácter histórico, el desarrollo de la industria y de las empresas, aún estaban en proceso de consolidación y de transición para alcanzar un nuevo peldaño en su desarrollo. De ahí, Smith, en su incunable obra de la economía, la Riqueza de la Naciones, concede importancia al progreso económico, siendo uno de los factores fundamentales del crecimiento económico, descansa en un concepto que, en cierto modo, fue institucionalizado por él, la división del trabajo. Desde esta óptica, la división del trabajo, contribuye a incrementar la producción, debido a la especialización y destreza que logra adquirir el trabajador durante su actividad laboral en la empresa. Al adquirir, el trabajador, mayores destrezas y habilidades en el trabajo, se produce un ahorro de tiempo en beneficio del empresario, con las tareas simplificadas y casi de carácter rutinaria conlleva a la invención de nuevas máquinas, elevando la productividad y generando un impacto en el desarrollo empresarial. En términos sencillos, Smith afirma que la división del trabajo descansa en la magnitud del mercado, el crecimiento de las ciudades y en la libertad del mercado como pilares fundamentales del progreso y del desarrollo industrial.

Por lo tanto, Smith considera importante el concepto de "hombre económico," al que mueve únicamente el interés personal, consiguiendo los fines que persigue por medio de la competencia. El interés personal no contradice, según el autor, los intereses generales, pues así es el orden natural (Karatiev y Rindynes, 1962).

Otro enfoque de los clásicos, aunque incipiente del desarrollo empresarial, se encuentra en David Ricardo, dado lo que concierne, al análisis sobre la maquinaria, para lo cual plantea, que la esperanza de obtener utilidad anima al empresario particular a la introducción de nuevas maquinarias, así "estará determinado por los efectos que de ella se esperan sobre las utilidades o, según sus palabras, sobre el producto neto, más bien, que sobre el producto bruto de la industria. Muestra que un aumento de maquinaria puede conducir al aumento del producto neto con una disminución simultánea del producto bruto." (Roll, 1999). Esto significa que con el aumento de la técnica en la producción se puede producir un desplazamiento de la mano de obra.

Desde la Posición de John Stuart Mill (1806 - 1873), el progreso empresarial se descompone en tres aspectos: aumento del capital, aumento de la población y mejoras en la producción. Bajo la influencia de Say, se esfuerza por resaltar que el empresario requería una capacidad especial, pero no la precisa de manera puntual (Terapuez y Botero, 2007)- Teoría del Emprendedor-. Afirma que el empresario debe: 
... tener una remuneración por su tiempo y su trabajo. La dirección de las operaciones comerciales e industriales suele recaer en la persona que suministra la totalidad o la mayor parte de los fondos con los que se realizan, y que, casi siempre, es la única interesada o la más interesada (al menos directamente) en el resultado. Para ejercer esta dirección con eficiencia, si la empresa es grande y complicada, se precisa una gran asiduidad en el trabajo y con frecuencia una habilidad más que ordinaria. Esta asiduidad y esta habilidad tienen que remunerarse (Mill, 1951).

[Mill] enfatizó más la importancia del emprendimiento para el crecimiento económico. Expresó que el desarrollo del entrepreneurship -espíritu empresarialrequiere habilidades no comunes y lamentó la inexistencia de una palabra en el idioma inglés que tuviera el mismo significado que el término "entrepreneur" en francés. (Mill, 1951).

A causa de esto se le considera quien introdujo el término entrepeneur en el uso general de los economistas ingleses.

\subsection{J. B. Say y la administración de los recursos}

Las contribuciones hechas por Jean Baptiste Say, al concepto de empresario y emprendedor, estaban fundamentados en su experiencia, dado que se consolidó como uno de los primeros empresarios de la mecanizada industria francesa de los hilados de algodón. El relaciona directamente al empresario con la actividad productiva industrial, e introduce la idea de administración y coordinación de los recursos como características centrales en la cotidianidad que el mundo capitalista va a desplegar a lo largo del siglo XX, no sólo en el interior de las actividades empresariales sino de manera análoga en cualquier organización que produzca esta sociedad (Ekenlund, Robert y Herbert, 2003). Al respecto dice: "Es aquel que unifica todos los medios de producción y logra, con el valor de los productos, el restablecimiento de todo el capital empleado más el valor de los salarios, intereses y rentas que paga, además de los beneficios que le pertenecen". Y precisa que para tener éxito debe poseer "discernimiento, perseverancia y cierto conocimiento del mundo de los negocios.

La experiencia personal de Say con la aparición del capitalismo industrial de su época le hace redescubrir la figura del empresario, de la que ya Cantillon había hablado, y que es presentado ahora como: el maestro-fabricante en la industria, el campesino en la agricultura, el comerciante en el comercio y en las tres ramas en general, como la persona que toma sobre sí la responsabilidad inmediata, el riesgo y la dirección de una empresa de trabajo, bien sea con capital propio o prestado. 
En este sentido el empresario utiliza con frecuencia algún capital de su propiedad, pero su retribución como empresario debe estar conceptualmente separada de su retribución como capitalista. Esto porque el empresario pone en movimiento todo tipo de trabajo, aunque no todas las clases de trabajos requieren las mismas grandes dotes empresariales. Lo que cuenta a la hora de pagar sus altas remuneraciones a los empresarios es la escasez del talento empresarial y el riesgo corrido por el empresario, riesgo no solamente de pérdida de fortuna sino también de pérdida de fama.

Por lo anterior el empresario hace cálculos aproximados a la cantidad del producto específico, el monto probable de la demanda y los medios de producción: unas veces deberá emplear un gran número de trabajadores, otras tendrán que comprar o encargar las materias primas, buscar trabajadores, encontrar consumidores y prestar, en todo momento, una gran atención al orden y a la economía. Por ello el empresario debe dominar el arte de la superintendencia y el de la administración. Debe tener una rápida destreza para el cálculo, que le permita comparar los gastos de producción con el probable valor del producto una vez terminado y puesto en el mercado. En el curso de todas estas complejas operaciones hay una gran cantidad de obstáculos que remontar, de ansiedades que reprimir, de contratiempos que subsanar y de expedientes que proyectar. Los que no posean una mezcla de todas estas cualidades necesarias fracasarán en sus empeños; sus empresas pronto se derrumbarán y su trabajo se retirará rápidamente del capital en circulación, dejando sólo a aquel que esté dirigido con éxito, es decir, con habilidad. La capacidad y el talento requeridos limitan, de esta manera, el número de competidores.

Por todo esto Say, junto con la actividad industrial, enriquece el concepto con ideas como la de perseverancia o actividad continuada que es realmente un elemento estructural en toda acción que hoy se considere como empresarial ${ }^{5}$.

\subsection{El pensamiento de los socialistas utópicos en el desarrollo empresarial}

A propósito de los Economistas de la corriente socialista, denominados por Carlos Marx como Utópicos, concebían a la sociedad en un cuadro fantástico del futuro del sistema socialista, las fantasías de los utópicos penetraron en todos los rincones de la vida humana, los problemas económicos y sociales querían resolverlos por el querer de ellos, es decir, las pasiones impulsan la historia de la humanidad como preconcebida por la divinidad.

\footnotetext{
${ }^{5}$ Ekelund, Robert y Hebert, Robert. "Historia de la Teoría Económica y de su Método" 3 Ed. Madrid, Mc Graw Hill. 2005.
} 
Desde esta perspectiva, Charles Fourier, uno de los representantes relevantes de esta corriente de pensamiento desarrolló una fantasía jamás conocida por la humanidad, "a pesar de su inmadurez y de su carácter fantástico, su teoría contiene el embrión de ideas valiosas, desarrolladas posteriormente por Marx. También atribuye una considerable importancia al desenvolvimiento de las fuerzas productivas al empleo de nuevos instrumentos de producción" (Karatiev y Rindynes, 1962). A pesar de su falta de ponderación, Fourier, estableció treinta y seis periodos de desarrollo social y cuatro periodos de desarrollo de la sociedad, comprendió acertadamente que cada período de transición del desarrollo de la sociedad a otro nuevo está relacionado con la invención de nuevos instrumentos de producción.

Fourier, en su afán de construir una sociedad idealista, elaboró un proyecto de organización que denominó las falanges, lo que debía ser la sociedad socialista, estructurado en la asociación de las disímiles clase sociales para armonizar las relaciones de producción en la sociedad, para organizar las falanges se requerían cuatro millones de francos y los capitalistas por su condición eran los llamados a proporcionar los recursos económicos, aporte este que los convertiría en accionista y miembros de la falange. Sobre este aspecto, Fourier, estableció un proceso de distribución de los ingresos producidos por la falange en tres partes, así: al capital, los obreros y el talento humano, de manera proporcional. Con este modelo de organización, Fourier creía y estaba convencido que acabaría con los males de la sociedad capitalista y alcanzaría un nivel de desarrollo empresarial, nunca antes visto por la humanidad.

Otro de los grandes pensadores en la sociedad utópica es Robert Owen, quienes lo consideraban el padre del sistema de producción industrial. Marx se refería a Owen como "el padre de las fábricas y de los bazares cooperativos". A los nueve años comenzó a trabajar en empresas comerciales. A los veinte años dirigía una fábrica de hilado de algodón en la ciudad Mánchester, Inglaterra. En ésta fábrica dio a conocer su talento de innovador e introdujo diversos perfeccionamientos técnicos, adquiriendo una connotada popularidad en los círculos industriales de Inglaterra. Como empresario de la época extendió el radio de acción en Inglaterra y abrió otra fábrica en la ciudad de New Lanark, donde también introdujo nuevos procedimientos técnicos para aumentar la producción a nivel interno, impulsó y organizó racionalmente la producción, también logró mejorar los problemas que padecían los obreros.

Robert Owen era un innovador perenne del periodo, la fábrica de Lamark se convirtió en modelo, no había instituciones que correspondieran a la democracia ni mucho menos policías y cárceles, elevó el nivel de vida de los obreros con respecto a otras empresas. También impulsó la construcción de vivienda de los obreros, se le considera el fundador de la caja de ahorro y de seguro, construyó 
las guarderías de los niños y las casas cuna e institucionalizó los comités sanitarios. Fue el pionero en reducir la jornada laboral, el legado histórico de Owen, ha servido a los empresarios modernos en sus propósitos de implementar lo que se puede llamar el desarrollo empresarial social. Además, su mayor aporte, al desarrollo empresarial, lo establece en su desmesurado propósito por defender los obreros, por las condiciones que padecían en las fábricas, lo indujo a una lucha abierta por una legislación fabril. También reclamaba la abolición del trabajo infantil en las fábricas, propuso la creación de unos inspectores fabriles pagados y estaba de acuerdo en reducir la jornada laboral en los adolescentes, en algunos casos, estas reivindicaciones tuvieron eco, debido a la labor titánica realizada por Owen dado por el proceso de metamorfosis que encarnó en la posición de empresario transformador.

En esta misma perspectiva sobre la corriente de los socialistas utópicos, merece en estima el legado de Saint Simón, de noble familia, ostentó el título de Conde, tuvo el privilegio de tomar de la fuente intelectual de uno de sus profesores célebres del pensamiento enciclopedista D`Alembert, fue contemporáneo de los sucesos revolucionario de Francia. Engels lo llamó, el hijo de la gran revolución francesa.

Saint Simón, pensó que estaba predestinado para hacer grandes transformaciones en la reconstrucción de la sociedad humana, incursionó en la ciencia con el propósito de descubrir las leyes del desarrollo social. Pensó en reformar la ciencia, con la idea que ésta podía reformar el régimen social y los males de la sociedad capitalista. En su interés por la consecución de reformar la ciencia y con los acontecimientos de la revolución francesa observó que la confrontación entre la aristocracia y la burguesa, no es más que la lucha de clase, concepto que descubre de manera imprecisa.

Es evidente que el concepto de empresario enunciado por Saint Simón lo manifiesta en la célebre parábola:

"Supongamos que Francia perdiera un buen día tres mil hombres, y entre ellos cincuenta físicos, cincuenta químicos, cien organizadores de la producción, etc. Tal pérdida sería para Francia catastrófica, convertiría al país en un cadáver, paralizaría su desarrollo ulterior; admitamos ahora que Francia perdiera tres mil hombres y entres ellos todos los duques y los aristócratas más célebres; esto provocaría únicamente lagrimas a algunos franceses, que son buenas personas, pero la perdida seria únicamente moral, sin consecuencias graves para el progreso económico del país" (Karatiev y Rindynes, 1962).

El gran mérito de Saint Simón consiste en reconocer la importancia del desarrollo industrial como la locomotora que jalona el progreso de la sociedad y la 
importancia que tienen los empresarios para el desarrollo empresarial presente y futuro. Bajo esta óptica consideró a los industriales integrados por los mismos industriales, comerciantes y capitalistas, en su opinión, consideraba que la nueva sociedad debería ser dirigida por los industriales talentosos y grandes capitalistas. Además, de ser partidario de una asociación donde el propietario de la producción no fuera el empresario, sino la colectividad o sea que el empresario debería trabajar bajo las directrices de la asociación.

Por último, el socialismo utópico - escribía Lenin - "criticaba la sociedad capitalista, la censuraba y maldecía, soñaba con su destrucción y fantaseaba en torno a un régimen mejor, tratando de convencer a los ricos de la inmoralidad de la explotación." (Lenin, 1905).

\subsection{El marxismo en el desarrollo empresarial}

Carlos Marx, descendiente de una familia judía de clase media, considerado por los opositores de su teoría, como el ideólogo del proletariado, el economista revolucionario que utilizó la economía política como un instrumento de la lucha política en contra del capital.

El aporte de Marx al desarrollo empresarial se puede constatar en el programa de la Liga de los Comunistas; que fue publicado en febrero de 1848 en Londres con el nombre de "Manifiesto del Partido Comunista". En este documento Marx no diferencia, el empresario del capitalista, no obstante, señala a la burguesía como la clase social propietaria de los medios de producción y pregona que ha desempeñado en la historia un papel alternativo revolucionario:

"La burguesía no puede existir sino a condición de revolucionar incesantemente los instrumentos de producción y, por consiguiente, las relaciones de producción, y con ello todas las relaciones sociales. La conservación del antiguo modo de producción era, por el contrario, la primera condición de existencia de todas las clases industriales precedentes. Una revolución continua en la producción, una incesante conmoción de todas las condiciones sociales, una inquietud un movimiento constante distingue la época burguesa de todas las anteriores. Todas las relaciones estancadas y enmohecidas, en su cortejo de creencias y de ideas veneradas durante siglos, quedan rotas; las nuevas se hacen añejas antes de llegar a osificarse, Todo lo estamental y estancado se fuma; todo lo sagrado es profanado, y los hombres, al fin, se ven forzados a considerar serenamente sus condiciones de existencia y sus relaciones reciprocas." (Marx y Engel, 1848).

Marx, sostuvo que con la llegada de la burguesía a los lugares más remotos del planeta, las antiguas industrias nacionales han sido destruidas y están 
destruyéndose continuamente por el incesante desarrollo de los instrumentos de producción y el surgimiento de nuevas técnicas de producir las mercancías que universalizan el intercambio entre naciones, $\mathrm{y}$ al constante progreso de los medios de comunicación y la baja de los precios de las mercancías constituyen el arma de la burguesía para demoler cualquier muralla de Jericó. En ese sentido plantea que:

"la burguesía, a lo largo de su dominio de clases, que cuenta con siglos de existencia, ha creado fuerzas productivas más abundante y más grandiosa que todas las generaciones pasadas juntas. El sometimiento de las fuerzas de la naturaleza, el empleo de la máquina, la aplicación de la química a la industria y a la agricultura, la navegación de vapor, el ferrocarril, el telégrafo eléctrico, la asimilación para el cultivo de continentes enteros, la apertura de ríos a la navegación, poblaciones enteras surgiendo por encanto, como si saliera de la tierra. ¿Cuál de los siglos pasados pudo sospechar siquiera que semejantes fuerzas productivas dormitasen en el seno del trabajo social?" (Marx y Engel, 1848).

Asimismo, Marx - decía - en el Manifiesto que, con la llegada al poder de la burguesía había triturado los vestigios de las fuerzas productivas del feudalismo, y ha acelerado en años luz el progreso de todas las diversas ramas de la industria:

“Ante nuestros ojos se está produciendo un movimiento análogo. Las relaciones burguesas de producción y de cambio, las relaciones burguesas de propiedad, toda esta sociedad burguesa moderna, que ha hecho surgir como por encanto tan potente medios de producción y de cambio, se asemeja al mago que ya no es capaz de dominar las potencias infernales que ha desencadenado con su conjuro. Desde hace algunas décadas, la historia de la industria y del comercio no es más que la historia de la rebelión de las fuerzas productivas modernas contra las actuales relaciones de producción, contra las relaciones de propiedad que condicionan la existencia de la burguesía y su dominación. " (Marx y Engel, 1848).

De esta manera la teoría de Marx permite caracterizar al capitalista y empresario, el innovador, como un actor social concreto. Éste se encuentra motivado por el afán de ganancia en una lógica de acción más maximizadora que satisfaciente.

Esta lógica de acción racional se expresa claramente en el análisis del pasaje de la producción artesanal a la producción industrial (Marx, 1987a). Para Marx, el objetivo que mueve al actor capitalista es la generación de ganancia, que depende de la generación de plusvalor. Por ello la tecnología como expresión concreta de 
la capacidad de conocimiento aparece con el desarrollo de las fuerzas productivas.

En este sentido, el cambio técnico está dado por la pretensión del capitalista de ampliar el capital variable respecto a la composición orgánica del capital (Marx, 1987b). No se trata entonces de una evolución predeterminada y exógena a la lógica económica, sino intrínseca a la praxis específica de uno de los actores fundamentales: el capitalista o empresario y el emprendedor o innovador. Además, reconoce la fuerza laboral como un actor no como un factor, introduce así mayor complejidad en el tipo de acción del capitalista, ya que en sus decisiones de innovación debe considerar la acción de otros actores (Elster, 1990, p. 152-153).

El concepto de empresario expuesto por Marx lo sustenta en la capacidad creadora de la burguesía moderna, con una mentalidad innovadora que busca aumentar la ganancia a través del movimiento permanente de las fuerzas productivas, como el desarrollo de nuevas formas, procedimientos y técnicas que en la lógica del cambio se constituyen incontrolables.

\section{El empresario y emprendedor enfoque pre - neoclásico}

Según el enfoque neoclásico, el empresario es aquel que cumple con la función de coordinar, organizar y supervisar un negocio. Es la persona que adquiere diversos factores productivos (trabajo, capital y tierra) y los combinan de una determinada manera en el proceso económico (función empresarial), para vender un producto que genere los ingresos suficientes con el fin de remunerar a los distintos factores y obtener un beneficio.

Durante al siglo XIX, Austria, Suecia y Alemania proporcionaron muchos teóricos de la economía, influyentes y ampliamente conocidos. Sobre la base de las primeras ideas de los fisiócratas, estos pensadores realizaron significativos progresos en la teoría del entrepreneur. Algunas de las contribuciones alemanas fueron las de J. H. Von Thunen (1783-1850), H. K. Von Mangoldt (1824-68), Gottleib Hufeland (1760-1817), y Adolf Riedel (1809-1872). Esta teoría, que aboga por la noción de beneficio, no fue ciertamente de aceptación unánime. Otros autores dudaron de la legitimidad de la existencia del provecho, pues este era concebido a la manera walrasiana, como un excedente, más allá, de lo que es el precio de los factores de la producción (James, 2002).

La generación de provecho, ganancia o excedente es uno de los motivos que justifica la labor y el talento del empresario. 


\subsection{León Walras y el papel del empresario}

Según Coriat y Weinstein $(2002,2005)$, la visión de empresa en el marco del enfoque neoclásico ortodoxo basado en Walras —enfoque marginalista- se sustenta en tres aspectos: a) el objetivo del análisis es la búsqueda de condiciones de equilibrio en situaciones de competencia e información perfecta, ausencia de incertidumbre y un determinado estado de las técnicas; b) las firmas funcionan bajo un esquema de racionalidad perfecta, lo que les permite tomar siempre decisiones acertadas y buscar el objetivo de maximizar beneficios; c) se privilegia el análisis del intercambio más que el de los procesos de producción.

En este contexto, la empresa tiene como principal función aplicar los factores de la producción a los insumos con el objeto de producir bienes y servicios. Por ello, desde el punto de vista neoclásico tradicional, los únicos datos del «ambiente» que debe conocer son precios de productos y factores. Lo que supone que la empresa realiza esta tarea eficientemente en tanto conoce, y puede aplicar de manera adecuada, todas las técnicas disponibles. También se asume que hay una cooperación fluida y ausencia de conflictos entre todos aquellos que están involucrados en el funcionamiento de la empresa. Derivado del enfoque neoclásico convencional de empresa, la actividad de los empresarios resulta irrelevante porque su participación se reduce a efectuar los cálculos que permiten maximizar beneficios a su empresa ante los cambios en los datos generados por el mercado.

El enfoque neoclásico tradicional supone que la actividad de los empresarios está determinada por las condiciones que enfrentan. En otras palabras, solamente refleja condiciones objetivas de los sectores y mercados en los que operan. En consecuencia, ante un mismo cuadro exógeno, todas las firmas tenderán a comportarse de modo similar; de igual manera, si las condiciones de mercado cambian también lo hará, homogéneamente, el comportamiento de las empresas.

\subsection{Los aportes Johann Heinrich Von Thünen}

Thünen, Terrateniente Alemán, más conocido como el padre de la economía espacial, por sus aportes al estudio de la localización de las actividades agrarias, consolidados en su obra Der isolierte Staat in Beziehung auf Landwirtschaft and Nationalokonomie (El estado Aislado), publicada en 1826. Se considera que rompió con el pensamiento económico de su tiempo, especialmente la escuela clásica inglesa. Al mismo tiempo, su obra retoma algunos de los principios de los autores del siglo XVIII y, contrariamente a la mayoría de los economistas de su época, sus análisis se basaban en observaciones empíricas, distintamente de los análisis abstractos realizados por aquellos. 
Es pertinente anotar que, para Von Thünen, es clara la relación entre el emprendedor y el beneficio, concebido este último sobre la base del riesgo y su ingenio. Por ello, "el emprendedor podía tener la doble característica de tomador de riesgo e individuo sumamente inteligente" (Rodríguez y Jiménez, 2005, p. 75). Es así como, Thünen integra la idea de Bentham del empresario - innovador, y la de Cantillón sobre el empresario que asume riesgos, de tal manera que al preguntarse si los emprendedores eran tomadores de riesgos o innovadores o si eran las dos cosas a la vez, termina respondiendo que se unen en una sola persona los dos atributos (Formaini, 2001, p. 5).

En este orden de ideas, Thünen "fue uno de los primeros economistas en afirmar que inicialmente la actividad empresarial consiste en asumir riesgos" (Freiling, 2005). Por esto define la ganancia del empresario por los siguientes elementos: beneficio menos interés del capital invertido, seguro contra pérdida y salarios de la dirección, y aclara que:

Este residuo consta de dos partes: primera, el pago por ciertos riesgos, especialmente las variaciones en los valores y las probabilidades de quiebra de toda la Empresa, que no puede ser asegurada contra este riesgo, y segunda, la extraproductividad del trabajo del elemento directivo, debido al hecho de que está trabajando para sí. (Knight, 1947).

El riesgo asumido por el empresario y su capacidad productiva para realizar innovaciones deben tener cierta contraprestación, por consiguiente, Thünen afirma que el empresario debe tener un ingreso que compense el riesgo asumido por las diarias contingencias que presenta el acontecer económico. Las noches sin sueño del empresario no son improductivas, pues sostiene que la necesidad es la madre de la invención (Terapuez y Botero, 2007)- Teoría del Emprendedor-. Precisamente por su preocupación se convierte en explorador, descubridor o inventor de su campo de actividad. Además, señala que en la noche, a diferencia de los empleados, el empresario no puede descansar tranquilamente hasta el día siguiente, porque él sigue pensando en cómo ampliar el mercado, disminuir sus costos y reemplazar los bienes que corren el riesgo de convertirse en obsoletos (Terapuez y Botero, 2007) - Teoría del Emprendedor-.

\subsection{Hans Von Mangoldt y el riesgo de ser empresario}

Economista alemán (1824-1868), autor expone una teoría sobre la renta generada por la capacidad emprendedora del empresario, la cual muestra en su obra $L a$ ciencia de la ganancia del empresario.

Tanto a Mangoldt como a Thünen se les considera en el ámbito austriaco-alemán, los primeros aportantes a la teoría del empresario quienes además son 
considerados los más prominentes teóricos del emprendimiento (Terapuez y Botero, 2007)- Teoría del Emprendedor-.

El tema sobre el empresario gira en torno al cameralismo, y el análisis de su función empresarial tuvo un lento desarrollo, aunque en forma constante, y culminó en la obra de Mangoldt, donde explica compleja y minuciosamente el beneficio. En este sentido "Analiza las bases y límites de los beneficios y concluye que una distribución asimétrica del conocimiento entre los actores económicos es la causa que explica por qué y cómo se obtienen los beneficios más elevados" (Freiling, 2005), aunque de igual manera considera que el beneficio del emprendedor será el pago por su habilidad y que dicho beneficio, a la vez, se compone de un grupo complejo de elementos únicos que divide en tres partes:

Primera, una prima sobre aquellos riesgos de tal naturaleza que no puedan ser eliminados mediante el seguro; segunda, el interés y los salarios del empresario, incluyendo únicamente los pagos por formas especiales de capital o esfuerzo productivo, que no admiten ser explotados por nadie que no sea su propietario; tercera, la renta del empresario. Esta última se subdivide en: a) renta del capital; b) renta del salario; c) renta de la gran Empresa, y d) renta del empresario en un sentido estricto. (Knight, 1947).

Luego de darse cuenta de la importancia del tiempo en los riesgos asumidos por el emprendedor, Mangoldt, incluye el tiempo como variable en la ecuación de la toma de riesgos que asume el emprendedor. Es así como, a "lo largo del proceso productivo, la mayor incertidumbre y, por lo tanto, el riesgo, afectarían la función del emprendedor [...] Mangoldt se anticipó a la distinción entre riesgo e incertidumbre que posteriormente desarrollaría Frank Knight" (Formaini, 2001). A mediados del siglo XIX, Mangoldt ofreció una teoría de la ganancia del emprendedor, entendida como la renta de la capacidad emprendedora o el talento especial, no rutinario y escaso, que utiliza en la adecuada combinación de factores. Estas primas a la escasez, que denominó Mangoldt, son posiblemente una expresión defectuosa, dado que, en últimas, los ingresos de los factores de producción no dependen solamente de su escasez y limitación. (Terapuez y Botero, 2007) Para él, "el emprendimiento y la innovación son aprobados como un factor importante de la empresa" (Rodríguez y Jiménez, 2005), por lo cual asocia al emprendedor con una persona que innova constantemente. 


\section{Contribuciones de los neoclásicos}

La escuela clásica finalizó con la llamada revolución marginal en la década de $1870 \mathrm{y}$, desde entonces, sus doctrinas centrales pasaron ser reconocidas como la renovación del pensamiento clásico o neoclasicismo (Blaug 1986). Durante este período, aproximadamente de 1880 a 1910, las producciones teóricas británicas y austriacas dominaron el pensamiento económico, con economistas representativos como Alfred Marshall (1842-1924), A. C. Pigou (1877-1959), Carl Menger (1840-1921), y Friedrich Von Wieser (1851-1926). Estos economistas, trataron el tema del empresario y emprendedor, pero no agregaron valor a la teoría de la actividad del entrepreneur, aunque utilizaron trabajos de la escuela fisiocrática y la clásica, aunque trataron extensamente los temas relacionados con el beneficio de la empresa (Wieser, 1967).

\subsection{Alfred Marshall y la empresa como factor de producción}

Para A. Marshall, la empresa significa uno de los agentes esenciales del desarrollo económico, y junto con John Bates Clark (1847-1938) se esforzaron por incluir al empresario dentro de sus modelos de crecimiento económico. Así lo demostró en su obra Principios de Economía, en donde explica los factores de producción, de cuya cooperación nace la oferta de productos o ingreso nacional, y son tierra, trabajo, capital y empresa.

De esta manera indica la existencia de la "organización" como un cuarto factor de producción, para hacer de la utilidad un ingreso del factor y "había considerado que el nivel de este dependía de la escasez más o menos acusada de la aptitud de los hombres para organizar" (James, 2002, p. 355). A estos hombres los denominaría Business management y su éxito se lo asignaría al hecho de poseer un sólido y robusto carácter para los negocios (Rodríguez A. , 1999). En este sentido, Marshall "hizo eco del sentimiento de J. B. Say en lo referente al trabajador superior, enfatizando en las capacidades de mando requeridas" (Rodríguez y Jiménez, 2005).

De igual manera, declaró que existe un cierto dividendo anual, formado por los productos materiales e inmateriales fabricados en un país en el curso de un año. Ese ingreso nacional nacía como resultado de la cooperación de los cuatro factores de producción, tierra, trabajo, capital y empresa. El problema de la distribución consiste en definir qué fuerzas determinan la distribución del dividendo nacional entre los cuatro factores de producción (Ferguson, 1979).

En términos de la ganancia, poco aporta; pues el empresario es el capitalista y las ganancias constituyen un ingreso sobre el capital. Es cierto que, en relación con esto, distinguió apenas la empresa como un cuarto factor en la producción, y así 
trazó una línea tenue entre tierra, trabajo, capital y empresa. La poca importancia prestada a la teoría de las ganancias a razón del riesgo y enfatizó en declarar que las ganancias son sólo un ejemplo de equilibrio entre la demanda y la oferta. En este caso, la demanda es la demanda de capacidad para los negocios, y la oferta, el total de esa capacidad. Manifestó que las ganancias a corto plazo son cuasi renta. A largo plazo un aliciente para la iniciativa (Ferguson, 1979).

Por otro lado, manifestó que los emprendedores son líderes por naturaleza y están dispuestos a actuar bajo las condiciones de incertidumbre que causa la ausencia de información completa. Al igual que Mill, aseguró que los entrepreneurs poseen numerosas habilidades especiales y que son pocas las personas capaces de definirse de esa manera. Sin embargo, "reconoció que una persona puede aprender y adquirir dichas habilidades” (Rodríguez y Jiménez, 2005).

También fue uno de los introdujo consideraciones morales en el desempeño de la función de empresario, aunque señala, que no había nada de malo en el deseo de acumular riqueza como símbolo de éxito en los negocios. Exaltó que la caballerosidad en los negocios debía incluir el espíritu del bien público, por lo cual correspondía a los economistas examinar si el empresario había acumulado su riqueza mediante mecanismos legales o fraudulentos. De allí en adelante, algunos autores han tendido a introducir consideraciones éticas en la reflexión teórica sobre la figura del empresario.

\subsection{Emprendedor como innovador Joseph Schumpeter}

Joseph Alois Schumpeter (1883-1950), de origen Austriaco, muy reconocido en la teoría económica por su obra Teoría del desenvolvimiento económico (1912), donde expone, con una visión moderna el papel que cumple el empresario como agente dinamizador y clave principal del crecimiento y desarrollo económico.

Schumpeter, en su visión sobre la dinámica del sistema capitalista incorpora sus teorías sobre el empresario, la innovación, el interés y el ciclo económico; consolidándolas en su obra cumbre. Esta teoría sobre del desarrollo económico da una explicación de los factores endógenos que producen el desarrollo del sistema económico, sin ignorar que los cambios también pueden ser exógenos. Pero su interés se centra en aquellos factores que provienen del interior del mismo, coincidente con Marx, en el estudio del cambio socioeconómico desde un modelo de desarrollo endógeno. Es así, que la interpretación Schumpeteriana del desarrollo o desenvolvimiento (alemán: entwicklung), debe entenderse con una doble significación: crecimiento y dinámica.

En consecuencia, el capitalismo dinámico, parte del modelo estático planteado por Walras, sin ciclos económicos. En este estado estacionario, según Schumpeter, sólo existen dos factores: la tierra y el trabajo que reciben 
remuneración; puesto que el capital no existe, por lo tanto, no hay ni intereses, ni beneficios, manejándose un nivel de certidumbre absoluto y la obtención de la información completa al estilo del mercado de competencia perfecta que, aunque no muestre crecimiento, si presenta movimiento.

Por consiguiente, supone la existencia de cinco factores que impulsan y alteran el cambio, del estado estacionario, estos, no son otra cosa que las innovacionesi: a) La introducción de un nuevo bien, b) La introducción de un nuevo método de producción, c) La apertura de un nuevo mercado, d) La conquista de una nueva fuente de aprovisionamiento de materias primas o de bienes semimanufacturados y e) La creación de una nueva organización de cualquier industria.

Estas innovaciones aparecen en el estado estacionario, y uno de sus impactos conduce a la generación de nuevas empresas; las cuales son asimiladas gradualmente por otras nuevas empresas o por empresas ya establecidas. En la medida en que se difundan y se asimilen las innovaciones por el aparato empresarial, se alcanzaría un nuevo estado estacionario; hasta tanto no se presenten nuevos procesos de innovación. Es aquí donde entra a jugar un papel importante el empresario, como el agente, encargado de realizar las innovaciones, concebirlas y hacerlas realidad en las empresas. Asimismo, el empresario, necesita de crédito de los bancos para introducir las innovaciones en las empresas; dado que, sin crédito no habría desarrollo. Por esto, el papel del sistema bancario es fundamental, puesto que juzga la solidez de los proyectos de innovación y financia las aventuras empresariales, y es quien asume los riesgos de los eventuales fracasos, y así, esa estrecha relación representa cuerpo y alma del sistema capitalista.

En este orden de ideas, una vez que el sistema supera la condición de estado estacionario por la aparición de las innovaciones, surge el beneficio empresarial y el monto del interés que se debe pagar. El beneficio aparece en el momento en que el empresario pague el crédito al banco, que es el remanente, después de pagar el principal y los intereses, obviamente el banco recibe la suma de los intereses pactada con el empresario.

De esta forma, se produce el desarrollo económico en el capitalismo competitivo, sin embargo, los cambios ocasionados por las innovaciones, desde la visión schumpeteriana, se mueve con tropiezos y nunca en forma continua, produciéndose rupturas en el sistema que afectan su dinámica. Esto lleva al estudio del ciclo económico; donde el desarrollo económico se da en forma de fluctuaciones y sucesivas aproximaciones que representan un movimiento ondulatorio. Así se presenta, porque las innovaciones aparecen en forma discontinua, en racimos. 
Los cambios en los ciclos generan algunos efectos secundarios sobre la demanda de empresas, derivadas de los cambios ocasionados por la aparición de las innovaciones. Entre estos efectos secundarios se pueden mencionar seisi. El primero tiene que ver con la expansión de nuevas industrias o de industrias ya establecidas como fruto de la aparición de nuevas innovaciones. El segundo, ocasionada por la aparición de nuevos, mejores instrumentos y equipos de producción. El tercero, derivado del aumento del ahorro de las empresas que han alcanzado beneficios, fruto de la aplicación exitosa de las innovaciones. El cuarto, como resultado de la mejora de sectores letárgicos, como fruto del mejoramiento industrial general. El quinto, por el logro de las economías de escala alcanzadas por empresas pioneras, que luego se van transmitiendo a otras empresas de la misma industria. Finalmente, por los beneficios alcanzados por las empresas que no han adelantado ninguna actividad innovadora.

Es así como se explica el funcionamiento y la dinámica del sistema capitalista, donde salta a la vista el papel jugado por el empresario que adelanta innovaciones, financiado por el sector bancario.

Schumpeter, considera al empresario como el gran protagonista del desarrollo económico, un agente capaz de responder creativamente a los cambios, a través, de innovaciones o nuevas combinaciones de factores de producción. En este sentido, el empresario, de Schumpeter, actúa en clave dinámica y desequilibradora. Su «proceso de destrucción creadora» supone la ruptura de un equilibrio establecido para imponer uno nuevo. En la nueva situación el empresario tendrá una posición de privilegio (poder de mercado) que resultará ser la recompensa por su innovación (nuevos productos, nuevos procesos, nuevos mercados, nueva fuente de aprovisionamiento, nueva organización). Pero la trascendencia de la función del empresario reside en la acción desequilibradora que impulsa el sistema económico hacia un proceso de desenvolvimiento terminología de Schumpeter - en el que cada nuevo equilibrio se determina en un nivel de crecimiento mayor.

En consecuencia, el empresario innovador era el agente clave en los procesos de desarrollo económico. Sin embargo, Schumpeter descargó de la responsabilidad única de la innovación al empresario innovador individual, haciendo una clara distinción entre el empresario innovador y el capitalista, el director o el propietario de la empresa. También lo distingue del inventor. El empresario trata de lograr realizaciones. En definitiva, ser empresario, no es para Schumpeter una profesión. Sólo se es empresario cuando se llevan a la práctica innovaciones, es decir, que gran parte de las innovaciones no hay que inventarlas, se encuentran presentes en la sociedad, Por tanto, el carácter de empresario es efímero y funcional. 
En cuanto al factor social, los empresarios no constituyen una clase social, como los terratenientes, los capitalistas y los obreros. Es decir, ser empresario no significa de por sí una posición de clase ni tampoco la presupone (pp. 87).

Desde el punto de vista de la función del empresario, Schumpeter, dice: "solamente se es empresario cuando se llevan a la práctica nuevas combinaciones, y se pierde el carácter en cuanto se ha puesto en marcha el negocio" (pp. 88). Así, al parecer, el creador también es devorado, en tanto que creador, por su propia creación: se es empresario para dejar de serlo. Se trata, entonces, de una función especial - la realización de nuevas combinaciones - que es "el privilegio de un tipo de hombres que son mucho menos numerosos que aquellos que disponen de la posibilidad objetiva de hacerlo". Un "tipo especial" de conducta y de persona (pp. 91) que nada contra la corriente (pp. 89) y, en ese sentido, es al simple gerente lo que la dinámica a la estática, lo que la innovación a la corriente circular o el equilibrio (pp. 92).

Según Schumpeter, durante la vida, un empresario debe enfrentar y sortear tres de obstáculos En primer lugar, una vez que comienza a nadar contra la corriente, la incertidumbre, demanda del empresario un mayor grado de "racionalidad consciente", que la acostumbrada en la corriente circular, basada más en las rutinas y en la experiencia previa. En segundo lugar, obstáculos psíquicos, "No es sólo objetivamente más difícil realizar algo nuevo que lo habitual y lo que ha sido probado por la experiencia, sino que el individuo siente repugnancia por ello" (pp. 95). En tercer lugar, obstáculos "del medio social contra aquel que desee hacer algo nuevo" que van desde "impedimentos legales o políticos" hasta la condena a "toda conducta desviada" (pp. 96).

También afirmó, que lo más importante de un sistema de mercado capitalista, es que recompensa el cambio, al beneficiar por medio de monopolios de corto plazo a quienes crean productos y procesos nuevos. Las ganancias que los empresarios consiguen de esta manera les permiten: 1) financiar actividades creativas para responder a las oportunidades que perciben; 2) superar tanto la naturaleza conservadora de quienes deben cooperar en el lanzamiento de productos nuevos como la oposición de aquellos cuyos mercados pueden sufrir a causa de estos productos; y 3) ampliar sus canales de distribución para que un gran número de clientes conozcan rápidamente los productos nuevos. Las ganancias a través de monopolios constituyen, para Adam Smith, una señal de ineficiencia económica; para Schumpeter, la evidencia de una actividad empresarial valiosa en una economía sana y dinámica (Nakamura, 2000).

Por último, la función empresarial innovadora es el factor más relevante de desarrollo económico y además, arrastra con su acción a un proceso de imitación al resto de los empresarios, en beneficio de los consumidores (O`Kean, 1989). 
En general, Schumpeter distinguía en la práctica cuatro tipos de empresarios: el fabricante- comerciante, el capitán de industria, el director y el fundador de la empresa. Por ello, el empresario, para Schumpeter, es el hombre innovador y de iniciativa, sea cual sea el lugar que ocupe. A pesar de ello, consideraba que nadie era empresario en forma permanente, sino algo temporal, que cualquiera podía llegar a alcanzar en un momento dado. Para Schumpeter, el empresario es quien realiza el acto empresarial. Destacando que la situación de los grandes empresarios estaba transformándose rápidamente: la función perdía importancia cada vez más y los obstáculos con que tropezaba en la realización de su misión disminuían progresivamente de intensidad. La humanidad se habitúa cada vez más fácil a las innovaciones, pues afirma que "la misma innovación se está reduciendo a la rutina" (Schumpeter, 1971).

Respecto al beneficio que percibe el emprendedor, no es un salario, sino un valor descontado de las ganancias por el incremento en el valor de los activos de la empresa. Para él, la cualidad de emprendedor sólo tiene sentido cuando se llevan a cabo nuevas combinaciones y se pierde el carácter en cuanto se ha puesto en marcha el negocio.

\subsection{Los riesgos y la incertidumbre de Frank Knight}

Frank Knight nació el 7 de noviembre de 1885 en Illinois (EE.UU.) y falleció en 1972. Es considerado uno de los fundadores de la llamada Escuela de Chicago, y como tal, uno de los más notorios exponentes norteamericanos de la ortodoxia clásica de la época, uno de los economistas más eclécticos y posiblemente el pensador más profundo y erudito en Estados Unidos.

En su trabajo de tesis doctoral en filosofía, publicado en 1921, con el nombre de Riesgo, incertidumbre y beneficios. El objetivo principal era analizar sus implicaciones a propósito de la controversia sobre la retribución empresaria, es por ello que trata de dar respuesta a las preguntas ¿Cuál era la distribución justa de los beneficios de una empresa? y ¿Los beneficios de una empresa corresponden enteramente a quien aporta el capital o al distribuirlo también se debe tener en cuenta la habilidad del emprendedor para conseguirlo? Dichas interrogantes, surgieron desde las propuestas de los economistas clásicos, sobre si la renta, el beneficio y el salario corresponden a la aportación de los factores tierra, capital y trabajo, respectivamente. Esta teoría fue replanteada por los neoclásicos, donde le dan prioridad al productor individual y no a la clase capitalista, la cuestión era si se igualaban la contribución a la producción y la remuneración que se obtiene de ella (Pradier y Serrano).

Para el periodo 1891-1904 Estados Unidos era sometido a huelgas cada vez más violentas, hecho que suscitó gran parte de la incertidumbre que se manejaba en la 
industria, y por otro lado los riesgos que asumían los que aportaban el capital y aportaban su propia destreza. Es por esto que se trataba de dilucidar si el beneficio de una empresa corresponde enteramente a quien aporta el capital o si se tiene que tomar en consideración, al distribuirlo, la aportación del empresario a su consecución.

Es en este momento cuando se identifica un agente que no solamente puede ser capitalista, sino, que, además posee un talento especial para los negocios y no había sido suficientemente considerado como un factor de la producción por la teoría económica precedente. Ese "nuevo" factor de producción era justamente el emprendedor o empresario (Terapuez y Botero, 2007)-Teoría del Emprendedor-. Así, Knight, da por hecha la existencia del emprendedor como una persona con gran influencia en la economía pero que lastimosamente hasta ese momento no se había tenido en cuenta en sus justas proporciones (Terapuez y Botero, 2007) -Teoría del Emprendedor-.

Antes de entrar a definir el empresario y emprendedor desde la óptica de Knight es necesario aclarar las interpretaciones del riesgo y de la incertidumbre, puesto que desde estas dos categorías se caracteriza y se le asignan funciones a cada uno.

Para Knight, el "riesgo" es la aleatoriedad con probabilidades conocidas que a la vez se pueden asegurar (Terapuez y Botero, 2007) -Teoría del Emprendedor- en tanto que la "incertidumbre" la define como la aleatoriedad con probabilidades desconocidas que no se pueden asegurar. En este sentido interrelaciona los beneficios y la empresa con la existencia de incertidumbre, asumiendo que existe incertidumbre mensurable, o riesgo propio e incertidumbre inmedible o incertidumbre. Por esta razón el riesgo es asegurable, mientras que la incertidumbre no, considerando, que ésta última hace más altas las utilidades; como consecuencia de los constantes cambios en los ambientes en que tiene lugar la actividad económica. Por ello, manifiesta que sin cambios no habría utilidades, sin embargo, sostiene que no es el cambio como tal, "sino la divergencia de las condiciones reales respecto de las que se esperaban y tomaron como base para organizar los negocios, lo que produce las utilidades" (Roll, 1996) (Terapuez y Botero, 2007) -Teoría del Emprendedor-.

Con relación a la incertidumbre, es asumida por un emprendedor cuando decide iniciar "una operación claramente arriesgada, lo hace porque cree que, como saldo final, ofrece una oportunidad atractiva" (Kizner, 2006), aunque considera que "el empresario, más que reducir la incertidumbre, asegura y garantiza una renta al dudoso o tímido y cuya actividad es prestar servicios productivos por una remuneración fija, esto es, el empresario es quien asegura a los propietarios de servicios productivos contra la incertidumbre y fluctuación de sus rentas" (Brunet y Alarcón, 2004). 
Por otro lado, la figura del empresario que se enfrenta a la incertidumbre, expresa Knight, constituye un agente muy dinámico que impulsa el desarrollo y promueve la innovación; por lo tanto, tiene un difícil encaje dentro del análisis de equilibrio estático (Gonzalez, 2004), dado que el medio en que el emprendedor realiza su labor es dinámico, en el cual, si se modifica una variable, también se modifican otras en mayor o menor medida.

Cuando Knight habla del juicio que el emprendedor tiene para los negocios y menciona que: El espíritu empresarial representa ese juicio que no puede ser evaluado en términos de su producto marginal, en consecuencia, no se le puede asignar un salario. Lo anterior se debe, porque el espíritu empresarial es un juicio para analizar los eventos más inciertos, tales como comenzar una nueva empresa, definir un nuevo mercado y quién lo va a llevar a cabo (Foss y Klein, 2004, p. 9; al respecto véase también Wood, 2005). Igualmente, Knight, menciona que:

... en nuestras decisiones hay una incertidumbre irreducible a cálculo, se da siempre la posibilidad de equivocarse (liability to err) que es lo que explica, justamente, la aparición de beneficios y su atribución al empresario [...] La gestión de la incertidumbre en la empresa es, por tanto, la función que distingue al empresario del mero gestor (manager). Prad (Pradier y Serrano).

En su obra, Knight, ve al empresario como la persona que toma a su cargo los riesgos no asegurables de la producción y, así, tiene un papel esencialmente dinámico. Desarrolla, así mismo, una teoría dinámica del beneficio empresarial. Estableció que los emprendedores siguen un proceso metódico para crear la empresa. Por eso lo consideró, el receptor del beneficio puro, como ingreso residual, después de haber descontado todos los pagos contractuales. Dicho ingreso residual es su recompensa por asumir la incertidumbre. El empresario, según él, es el capitalista que busca su beneficio en un mercado dinámico, y que no teme asumir riesgos. En el mismo sentido, Knight:

... proveyó dos grandes contribuciones al pensamiento emprendedor: la primera asociada enfáticamente a la distinción entre los riesgos asegurables y la incertidumbre no asegurable; la segunda, al adelantar una teoría de las ganancias que relaciona la incertidumbre no asegurable con el veloz cambio económico, por un lado, y con las diferencias de la habilidad empresarial, por el otro. (Rodríguez y Jiménez, 2005).

En síntesis, Knight distingue entre riesgo e incertidumbre. Por una parte, riesgo es lo objetivo y susceptible de ser medido, por lo cual puede ser incluido en los costos de la empresa, pero también se puede prevenir y disminuir mediante la constitución de seguros. Por otra parte, la incertidumbre es de carácter subjetivo $\mathrm{y}$, es precisamente, la que permite explicar y justificar la función del empresario. 
Respecto al riego, que asume el emprendedor, no significan nada si la incertidumbre puede ser asegurada. Ello, hace que prácticamente el emprendedor, que no asume riesgos sea en realidad un administrador. Es en esta condición que entra a caracterizar al emprendedor y le asigna siguientes atributos:

Tabla 2. Características y atributos del emprendedor de Frank Knight.

\begin{tabular}{|c|c|}
\hline \multirow{10}{*}{ EMPRENDEDOR } & $\begin{array}{l}\text { Persona inteligente que asume riesgos e incertidumbre y } \\
\text { asegura al dudoso o tímido }\end{array}$ \\
\hline & $\begin{array}{l}\text { Energía indomable, gran optimismo, autoconfianza y } \\
\text { mucha fe }\end{array}$ \\
\hline & Creatividad e imaginación \\
\hline & Tenacidad y persistencia \\
\hline & $\begin{array}{l}\text { Los emprendedores no se hacen, sino que nacen. } \\
\text { Sostiene que la habilidad para los negocios es en algún } \\
\text { grado heredada }\end{array}$ \\
\hline & Efectividad para el logro de beneficios \\
\hline & Agentes de cambio e innovación \\
\hline & El dinero es su mayor motivación \\
\hline & Conocimiento de sí mismo y del sector \\
\hline & $\begin{array}{l}\text { El éxito del emprendedor depende de tres elementos: } \\
\text { capacidad, esfuerzo y suerte }\end{array}$ \\
\hline
\end{tabular}

Fuente: citado en Tarapuez Chamorro, Edwin, Zapata Erazo, Jairo Andrés And Agreda Montenegro, Esperanza. Knight and his contributions to the entrepreneur theory. estud.gerenc., Jan./Mar. 2008, vol.24, no.106, p. 83-98. ISSN 0123-5923. Adaptado por Autores.

Adicionalmente establece que los emprendedores siguen cuatro pasos para crear la empresa, así (Wood, 2005, p.32): Estimación de la demanda futura que se quiere satisfacer, Estimación de los resultados futuros de las acciones que intentan satisfacer esa demanda, Evaluación de la exactitud de las estimaciones y la probabilidad de alcanzarlas, y la Selección del plan que se considera tiene mayor probabilidad de éxito.

Por último, Knight, no hace una clara distinción entre emprendedor y empresario, sólo desde el punto, en el cual cada uno asume el riesgo o la incertidumbre, aunque expone que el empresario o capitalista, dueño de la empresa es quien asume el riesgo y tiene un rol diferente al de director de la empresa. 


\section{El institucionalismo de John Kenneth Galbraith en el desarrollo empresarial}

Con el vertiginoso desarrollo del capitalismo en los Estados Unidos durante el siglo XX, el célebre economista, John Galbraith, del partido Demócrata, manifiesta que hay una mutación en las grandes corporaciones empresariales del mundo. Según Galbraith, el propietario de la empresa no tiene el poder de decisión como en el periodo precapitalista; las decisiones están determinadas por un grupo de técnicos y expertos profesionales del área de la administración y la economía, los cuáles constituyen el axis de las corporaciones modernas. A este grupo de técnicos y profesionales expertos en los disímiles temas empresariales para la toma de decisiones, Galbraith, lo llamó tecnoestructura.

Para J. Galbraith, la tecnoestructura, con su comportamiento y toma de decisiones en la empresa, modifica radicalmente las reglas del sistema capitalista. Además, reduce, las relaciones de la gran empresa con el Estado, y los más importante, determina las necesidades del consumidor a través de la publicidad en los medios de comunicación, con lo cual, el poder del consumidor se pierde.

Al mismo tiempo, la tecnoestructura, no tiene como finalidad esencial la obtención del máximo beneficio, su interés es hacer crecer la firma y posesionarla en el mercado, al igual que fortalecer la investigación científica en los diferentes campos, siendo sus frutos usufructuados por el sector privado, aquí la tecnoestructura trata de confundir los propósitos con los del Estado. Galbraith, reitera su tesis de la tecnoestructura en que hay una abismal diferencia entre la:

“empresa muy grande y la empresa de los manuales de economía es una diferencia de estructura. Es aquí donde interviene la tecnoestructura. En la gran empresa las decisiones más importantes son tomadas no por una persona aislada, sino por muchas personas. Nadie tiene por si solo todos los elementos necesarios para decidir el lanzamiento de un producto, la apertura de una fábrica suplementaria o la implementación en nuevos mercados. Se hace necesario acudir a los conocimientos, a la experiencia y al juicio de los gerentes, de los directores comerciales, de los ingenieros, de los científicos, de los abogados, de los contables, de los jefes de personal y de todos los de más depositarios de un saber especializado. Cada cual contribuye aportando la parcela de su experiencia de especialista." (Glabraith, 2000).

De igual modo asegura Galbraith que con el "desarrollo de la empresa la tecnoestructura se hace al poder. La razón es evidente: sólo aquellos que poseen los conocimientos necesarios para participar en el proceso de decisión ejercen influencia." (Galbraith y Salinger, 2001). 


\section{Los apóstoles del liberalismo en el desarrollo empresarial: Mises y Hayek}

Mises, "concebía la economía como un proceso de mercado donde el empresario o la conducta empresarial de los agentes económicos, desempeñan el principal papel” (Mises L, 2003). Del mismo modo, afirma que, en una economía dinámica, los empresarios no aciertan en sus previsiones, lo que lleva a que algunos de ellos obtener pérdidas y otros beneficios. En su defensa descomunal de la economía de mercado, Mises sostiene que, el "capitalismo estimula la innovación; cualquier perfeccionamiento de los sistemas de producción lleva aparejado el lucro consiguiente; quienes se aferran perezosamente a métodos periclitados sufren pérdidas patrimoniales; aquellos que estiman hacer algo mejor que los demás no tropiezan con cortapisa alguna para poner de manifiesto tal habilidad" (Mises L, 2003). En ese mismo sentido, plantea que los procesos de innovación e invento en la producción empresarial están soportados por el proceso de acumulación y el ahorro, sobre este punto dice:

"Todo avance por el camino de la prosperidad es fruto del ahorro. Los ingeniosos inventos resultarían inútiles, en la práctica, si los factores de capital preciso para su explotación no hubieran sido previamente acumulados mediante el ahorro. Los empresarios invierten el capital, ahorrado por terceros, con miras a satisfacer del modo mejor las más urgentes y todavía no atendidas necesidades de los consumidores. Al lado de los técnicos, dedicados a perfeccionar los métodos de producción, desempeñan, después de quienes supieron ahorrar, un papel decisivo en el progreso económico. El resto de los hombres no hace más que beneficiarse de las actuaciones de estos tres tipos de adelantados.

Cualquiera que sea su actividad, el hombre de la calle no pasa de ser simple beneficiario de un progreso al que nada ha contribuido" (Mises L. v., 2011).

El desarrollo empresarial de Mises, gira alrededor de los empresarios como actor principal que contribuye a dinamizar la activad económica, los ahorradores y los técnicos estos últimos son los encargados de transforman y perfeccionan los procesos de producción, para que los consumidores disfruten de mejores productos en las economías de mercado.

Para el adalid de la economía de mercado, Hayek, su teoría no se centra en el empresario en sí, sino en la importancia que tiene el mercado para trasmitir la información requerida por los empresarios. El punto clave está en saber cómo los individuos obtienen la información, es decir, la existencia de una tendencia hacia el equilibrio económico implica que las expectativas que se forman los agentes económicos son acertadas (Hayek, 1937). 


\section{Conclusiones}

El objetivo planteado en este estudio se alcanza porque recoge las contribuciones que las diferentes escuelas económicas y sus principales exponentes hicieron en la construcción del concepto de empresario y emprendedor, destacando sus argumentos sobre el rol y las funciones que desempeñan en la sociedad y en la empresa. Este sirve de escenario para determinar la caracterización de empresarios y emprendedores actualmente.

Desde los postulados mercantilistas, caracterizados por la acumulación incesante de riqueza, se erigió el concepto de empresario y emprendedor, aunque no hay una clara diferenciación, pero, sobresale se afán egoísta y la búsqueda del lucro, a través de los negocios. Por consiguiente, empresario y emprendedor, son representados como mercaderes y negociantes o comerciantes.

Con la fisiocracia se encuentran se resalta la vitalidad del empresario para la actividad económica de un país. Precisamente, Richard Cantillón, es quien introduce el concepto de empresario partiendo de la función que cumplen las empresas en los mercados organizados e interrelacionados. En este sentido, la dinámica del mercado, dada por la competencia para en ganar clientes, muestra la viveza del empresario para reaccionar ante los movimientos de precios en los mercados. En este sentido, el empresario, es un estudioso de los cambios y reacciones que le imprimen los precios al mercado, es decir, aquel que busca oportunidades. No obstante, precisó entre empresario capitalista, como el propietario, fabricante o comerciante y el emprendedor, como el que depende de su trabajo y toma ventaja de la incertidumbre y de las condiciones de riesgo del mercado.

Aquí se aprecia un aporte fundamental en el rol del empresario como el dueño del capital, que además combina y coordina los medios de producción para alcanzar resultados. Así, la actividad empresarial, determina al empresario como gestionador de recursos que se ve enfrentado al problema del riesgo y la incertidumbre con las cualidades del emprendedor.

Los aportes de los clásicos, presentan un empresario como propietario o capitalista, que, muestra similitud al que presentan los mercantilistas, pues, quieren sacar del mercado el beneficio máximo. Sin embargo, el elemento diferenciador, tal como lo expone Smith, es el aumento de la productividad en el trabajo.

En este punto, se destaca el desarrollo de las habilidades del trabajador, como consecuencia de la especialización. De esta manera, aumentar la productividad del trabajo, es resultado de la especialización; lo cual se puede definir como el producto de una mejora tecnológica o innovación. A raíz de este se puede inferir 
que el empresario capitalista, sin expresarlo, es un emprendedor, que busca acrecentar el rendimiento del trabajador para maximizar el beneficio empresarial. Asimismo, A. Smith, en su obra la Riqueza de la Naciones, precisa la división del trabajo es un factor del crecimiento económico, asimismo, pilar fundamental del progreso y del desarrollo industrial.

Para el caso D. Ricardo, complementa lo dicho por Smith, pero enfatiza, sobre la incidencia del aumento en la técnica de producción y de la maquinaria, sobre el aumento del producto neto del empresario, no obstante, advierte sobre el desplazamiento de la mano de obra. Tomando en cuenta la posición de J. S. Mill, el progreso empresarial, se debe al aumento del capital, la población y las mejoras en la producción. En este sentido, el empresario, requiere de una capacidad especial. Respecto, al emprendedor, Mill, lo muestra, como pieza clave del crecimiento económico, que requiere de habilidades no comunes, y a quien se le atribuye el desarrollo del entrepreneurship o entrepreneur, en francés.

En general, los clásicos, sin precisarlo anotaron tres aspectos claves para diferenciar empresario y emprendedor. Primero que, a través de la especialización del trabajo, sin separarse del mercantilismo, detecta que el aumento de la productividad determina el crecimiento empresarial y nacional. Segundo el mejoramiento técnico y las nuevas máquinas influyen en el aumento de producto neto y el tercero, el más claro de todos, empresario tiene capacidad y el emprendedor, la tiene, pero es poco común.

Por el lado de Say, relaciona al empresario con administración y coordinación de recursos en la empresa industrial. Adicionalmente, precisa, que, un empresario, es exitoso si tiene discernimiento, perseverancia y conocimiento del mundo de los negocios. Por lo anterior, el empresario, de Say, asume la responsabilidad, el riesgo y la dirección de la empresa, para lo cual es necesario el talento empresarial. Respecto al emprendedor, no especifica sus características, pero se infieren, del talento que debe tener un empresario para hacer negocios.

Con la entra a los socialistas utópicos y su afán de en solucionar todos los problemas de la sociedad capitalista, Fourrier, con base en los periodos de desarrollo social, determinó que la transición de una etapa a otra estaba relacionada con la invención de nuevos instrumentos de producción. Aunque no lo explícita, se puede inferir que, de los periodos de desarrollo social, asimilados a los ciclos económicos, unas empresas desaparecen y otras nacen; estas eran el producto de la capacidad de los emprendedores.

Por el lado del empresario, se puede tomar como el capitalista que proporciona los recursos económicos para la creación de la falange (Unidad productiva), en la que también interviene el talento humano y los obreros, entre los cuales se hace la distribución de los ingresos producidos. Esta realidad ideal, muestra la 
alternativa que tiene la sociedad de mejorar su condición con el impulso del desarrollo empresarial

Otro de los industriales utópicos, Robert Owen, un empresario industrial con sentido cooperativo. Owen integra el empresario y el emprendedor, dado, su talento innovador para proponer cambios y procedimientos técnicos para aumentar la producción; pero, además, demostró sus habilidades como empresario, cuando impulsó y organizó racionalmente la producción, para mejorar los problemas de los obreros. Su visión empresarial social, lo llevó a poner en práctica su capacidad emprendedora, dando impulso a la construcción de vivienda de los obreros, fundando la caja de ahorro y de seguro, creando las guarderías para niños y las casas cuna e institucionalizar los comités sanitarios, entre otros aspectos atinentes a los derechos de los trabajadores y del trabajo infantil. El talento de Owen lo respalda, Saint Simón, cuando expresa que a falta de organizadores de la producción sería catastrófico para el progreso económico de una nación. Por consiguiente, destaca el papel que tiene los empresarios industriales como jabonadores del progreso social, a tal punto, que asegura el futuro de la sociedad, sólo, si es dirigida por los industriales talentosos y grandes capitalistas.

El aporte de Marx, al desarrollo empresarial, inicia, asumiendo que el capitalista es empresario, lo cierto, es que su motivo principal es la generación de ganancia. Este capitalista, que representa, la burguesía, tiene como función dinamizar el cambio de los instrumentos de producción y, en consecuencia, las relaciones de producción y, asimismo, las sociales. De esta forma se suscitan los más grandes cambios en las estructuras productivas. También, Marx, representa el talento emprendedor en la capacidad de conocimiento que se materializa en la tecnología, como un elemento transformador de las fuerzas productivas. De hecho, la burguesía-empresarial genera unas relaciones que por sí solas crean nuevos y potentes medios de producción.

Por lo que se refiera a los pre-neoclásicos, el empresario, cumple con la función de gestionar los recursos básicos de la economía con la finalidad de producir bienes, para luego vender, remunerar los factores y obtener un beneficio. Con base en lo anterior, Walras, parte de que la empresa desarrolla la función de producción y el empresario bajo la racionalidad perfecta necesita conocer los precios de los productos y los factores, de tal manera, que siempre produce baja condiciones eficientes y sin incertidumbre. En relación con el empresario, su papel se reduce sólo realizar los cálculos para medir el beneficio y maximizarlo tomando en cuenta los cambios que se presentan en el mercado.

Al igual que lo planteó Cantillón, emprendedor y empresario, con Thünen, se fusionan en una sola persona, es decir, el empresario como tomador de riesgos y como innovador. En este sentido, el esfuerzo del empresario, se retribuye por su 
capacidad para hacer innovaciones, puesto que el empresario no descansa, pensando en cómo ampliar el mercado, disminuir sus costos y reemplazar los bienes que corren el riesgo de convertirse en obsoletos. Adicionalmente, Mangoldt, aduce sobre la renta, que genera la capacidad emprendedora, dado, que se ve afectada por la incertidumbre y el riesgo; dicha renta, se da por o el talento especial y escaso que el emprendedor materializa en la innovación constante.

A continuación, Marshall, incluye a la empresa como factor de producción y agente esencial del desarrollo económico. Sin embargo, el empresario, es el capitalista, su ganancia es un ingreso sobre el capital. En torno a los emprendedores, Marshall, los llamó líderes por naturaleza, que actúan en condiciones de incertidumbre, como lo dijo Cantillón, y, Mill, los emprendedores poseen habilidades especiales.

Desde la postura de Schumpeter, la posición del empresario aparece como dinamizador y clave principal del crecimiento y desarrollo económico. En contradicción con el estado estacionario de Walras, propone la dinámica y el cambio provocada por las innovaciones, donde el empresario de encarga de concebir las innovaciones y las hace realidad en las empresas. En consecuencia, las innovaciones justifican el beneficio empresarial. Las innovaciones producen cambios, pero, también rupturas que afectan su dinámica desequilibrada que se resume en el «proceso de destrucción creadora», mediante cual desaparecen y nacen nuevas empresas. Aquí, Schumpeter, le da privilegios empresario innovador individual, no obstante, propone una clara distinción entre el empresario innovador y el capitalista, el director o el propietario de la empresa. En definitiva, el innovador propaga el cambio, mientras que el capitalista la financia. Además, identifica cuatro tipos de empresarios: el fabricantecomerciante, el capitán de industria, el director y el fundador de la empresa y en cualquiera de ellos, el empresario, es hombre innovador y de iniciativas.

Retomando los elementos anotados por Cantillón en relación en con el riesgo y la incertidumbre que enfrenta el empresario, Frank Knight, analiza sus implicaciones en la retribución empresarial. En este sentido, se identifica un agente, que, además, de ser capitalista, tiene un talento especial para los negocios. Respecto al emprendedor, lo exalta por la gran influencia que ejerce en la economía. Coincidiendo con Schumpeter, Knigth, explica que le empresario enfrenta la incertidumbre, y se constituye un agente dinámico que impulsa el desarrollo y promueve la innovación; porque, del espíritu empresarial, se vale para hacer una nueva empresa o definir un nuevo mercado, gestionado la incertidumbre y el riesgo. En síntesis, Knight distingue entre riesgo e incertidumbre. Por una parte, la incertidumbre de carácter subjetivo explica y justifica la función del empresario. Por otra, los riesgos que asume el emprendedor no tienen significado si la incertidumbre es asegurada. 
Con la corriente institucionalista, de J K. Galbraiht, aparece el concepto de tecnoestructura, los cuales tienen a su cargo los temas empresariales y la toma de decisiones; cuya función principal, es hacer crecer la empresa y posicionarla en el mercado. Para la corriente institucionalista se pierde el papel del empresario y del emprendedor, dado que estos son asumidos por la tecnoestructura. Por el contrario, Mises, del liberalismo económico, muestra al empresario como agente económico, que pierda o gana, dependiendo del acierto de las previsiones que haga sobre la dinámica del mercado. También, exalta el capitalista que estimula la innovación para aumentar el lucro. En este sentido el empresario es, actor principal, contribuye con la dinámica de la activad económica. Por el lado de Hayek, la cuestión no está en el empresario, sino en la información, que manejan los agentes a través del mercado, de tal manera, que les permita tomar las decisiones más acertadas.

\section{Referencias}

Brunet, I., y Alarcón, A. (2004). Teorías sobre la figura del emprendedor. Recuperado de http://www.bib.uab.es/pub/papers/02102862n73p81.pdf

Caldera, J., Rodríguez, F., y Moreno, J. (s.f.). Manual guía para agentes multiplicadores en estímulo y desarrollo de capacidades emprendedoras. Recuperado de http://www.coronelsuarez.gob.ar/civitas/modulos/noticias/adjuntos/adjunto_20 720_5.pdf

Calvin, K., y Francis, R. (1999). Coverage of Entrepreneurship in Principles of Economics Textbooks: An Update (Spring 1999), 184-188. Journal of Economic Education 30, No. 2, 184-188.

Ekenlund, J., Robert, B., y Herbert, R. (2003). Historia de la Teoría Económica y de su Método. Bogotá: McGraw Hill.

Elkjaer. (1991). citando a Helen Verin. La maquinaria del proceso capitalista: los entrepreneurs 1 en la teoría económica

Ferguson, J. (1979). Historia de la economía. México: Fonde de Cultura Económica.

Formaini, R. (2001). he engine of capitalist process: entrepreneurs in economic theory. Economic and Financial Policy Review, Q IV, 2-11 Recuperado: http://www.dallasfed.org/research/efr/2001/efr0104a.pdf .

Freiling, J. (2005). Research on entrepreneurship development in Germany: what are the lessons for developing countries? Obtenido de Recuperado: http://frontpage.cbs.dk/ckg/upload/CKG-WP\%202004-11.pdf

Galbraith, J. K., \& Salinger, N. (2001). ntroducción a la economía: una guía para todos (o casi). Barcelona: Critica. 


\section{EMPRENDEDOR Y EMPRESARIO: UNA CONSTRUCCIÓN DESDE LA DINÁMICA DEL PENSAMIENTO ECONÓMICO}

Glabraith, J. K. (2000). El Crash de 1929. Barcelona: Ariel S.A.

Gonzalez, F. J. (2004). Incidencia del marco institucional en la capacidad emprendedora de los jóvenes empresarios de Andalucía. Tesis de doctorado no publicada. Sevilla: Universidad de Sevilla.

Hayek, F. v. (1937). “Economía y Conocimiento”,. Economica 4, No. 13, 35-54.

Heredira (2013). Empresario. Colombia: Club de ensayos.

Kantis, H. (2008). La cultura del emprendimiento en América Latina. Washington D.C.: Banco Interamericano de Desarrollo.

Karatiev, N., \& Rindynes. (1962). Historia de la doctrinas Económica . México: Grijalbo.

Kirzner, I. (1997). "Entrepreneurial Discovery and the Competitive Market Process: An Austrian Approach”. Journal of EconomicLiterature 35, No. 1, 60-85.

Kizner, I. (2006). Entrepreneurial discovery and the competitive market process: An Austrian approach. Autria: In The Journal of Economics Literature.

Knight, F. (1947). Riesgo, incertidumbre y beneficio. Madrid: Aguilar.

Lenin, V. (1905). Sobre el arte y la literatura. Madrid: Ediciones Jucar.

Londoni, J. S. (2006). Empresario y capitalista: nota para una teoría austriaca de la firma. Journal of Management for Value Vol $1 N^{\circ} 2,26$.

Marx, K., y Engel, F. (1848). Manifiesto del partido comunista.

Mill, J. S. (1951). Principios de Economía Política; con algunas de sus aplicaciones ala filosofía social. México: Fondo de Cultura Económica.

Mises, L. (2003). Una interpretación de la evolución social y económica. Madrid: Unión editorial S.A.

Mises, L. v. (2011). La Mentalidad Anticapitalista. Barcelona: Unión Editorial S.A.

Nakamura, L. (2000). Economics and the new Economy. The Invisible Hand Creative Destruction. Philadelphia: Federal Reserve Bank of Philadelphia.

O’Kean, J. (1989). Aportaciones a la teoría de la función empresarial. Boletín de estudios Económicos No. 136, 127-149. 
Pradier, P.-C., y Serrano, D. T. (s.f.). Obtenido de Disponible en: http://www.uned.es/personal/dteira/docs/knight.pdf

Ramírez, C. (2002). Fundamentos de Administración. Caldas: ECOE Ediciones.

Rodríguez, A. (1999). La lógica originaria del emprendedor. Barcelona: IESE.

Rodríguez, C., y Jiménez, M. (2005). Emprenderismo, acción gubernamental y academia: revisión de la literatura. Innovar, 73-89.

Roll, E. (1999). Historia de las doctrinas económicas. México: Fondo de cultura Económica.

Schumpeter, J. (1971). Capitalismo, socialismo y democracia. Madrid: Aguilar.

Terapuez, E., y Botero, J. J. (2007). Algunos aportes de los neoclásicos a la teoría del emprendedor. Cuadernos de Administración, 39-63.

Von Mises, L. o., y Kirzner, I. (1973). Competition and Entrepreneurship. Chicago: University of Chicago Press.

Wieser, F. v. (1967). Social Economics. (Nueva York: Augustus Kelley), orig. pub 1914.

Zimmerer, T., \& Scarborough, N. (1996). Entrepeneurship and the new venture formation. Prentice Hall.

\footnotetext{
i Schumpeter, no solamente considera como única fuente de cambios endógenos a la innovación, identifica realmente otras dos. Una primera derivada del crecimiento de la población (8C, p. 74) y una segunda fuente derivada de las oscilaciones propias del ciclo económico (Oakley. 1990, p. 80)

ii Vid. Schumpeter (1983, b) p. 44
} 